\title{
Joint use of echosounding, fishing and video techniques to assess the structure of fish aggregations around moored Fish Aggregating Devices in Martinique (Lesser Antilles)
}

\author{
Mathieu Doray ${ }^{1, \mathrm{a}}$, Erwan Josse $^{2}$, Paul Gervain ${ }^{3}$, Lionel Reynal ${ }^{4}$ and Josselin Chantrel $^{4}$ \\ 1 IRD/Ifremer, US Acoustique halieutique, Centre IRD de Bretagne, BP 70, 29280 Plouzané, France \\ 2 IRD, US Acoustique halieutique, Centre IRD de Bretagne, BP 70, 29280 Plouzané, France \\ 3 POLKA, Rue Authe 2, 97100 Basse-Terre, Guadeloupe \\ ${ }^{4}$ Ifremer, Laboratoire Ressources Halieutiques Antilles, Pointe Fort, 97321 Le Robert, Martinique
}

Received 27 March 2007; Accepted 27 June 2007

\begin{abstract}
From April 2003 to April 2004 monthly sea surveys were conducted around 2 fish aggregating devices (FADs) moored at 2000 and $2500 \mathrm{~m}$ depth in Martinique (Lesser Antilles). The use of a dual frequency splitbeam echosounder combined with an underwater camera and fishing methods allowed assessment of average space and time distribution of pelagic fish aggregated beneath the FADs, as well as identification of their overall size and species composition. At daytime, 4 fish aggregations were identified at each FAD, representing 4 distinct types: i) an aggregation of small juvenile tuna (mean fork length, FL: $30 \mathrm{~cm}$ ) observed very close to the surface in $25 \%$ of daytime periods; ii) a small surface aggregation dominated by carangids, Caranx crysos, present in $65 \%$ of daytime periods; iii) a large subsurface aggregation observed during all daytime periods: this aggregation appeared to be primarily comprised of $58 \mathrm{~cm}$ FL blackfin tuna (Thunnus atlanticus), mixed with yellowfin (Thunnus albacares) and skipjack (Katsuwonus pelamis) tunas of the same size; and iv) sub-surface scattered large predators (mainly blue marlin, Makaira nigricans) present in $10 \%$ of daytime periods. A smaller sub-surface aggregation comprised of medium tuna mixed with "extranatants" (fishes which remain within 10 to $50 \mathrm{~m}$ of a FAD) was observed in $75 \%$ of night-time periods, whereas unidentified scattered fishes were detected from 70 to $400 \mathrm{~m}$ depth. The low daytime vulnerability of medium sub-surface tunas to applied line techniques leads us to assume that their feeding motivation was low during daytime. These tunas could preferentially feed on mesopelagic organisms during night-time and transition periods around Martinican moored FADs. Local fishermen mainly targeted the large scattered predators using very small tunas as living bait. The sub-surface tuna aggregation hence appeared to be currently unexploited by local fisheries, though it represented the large majority of the pelagic biomass around the moored FADs.
\end{abstract}

Key words: Fish aggregating device / Acoustics / Underwater video / Small scale fishery / Aggregative behaviour / Tuna / Lesser Antilles

Résumé - Étude de la structure des agrégations de poissons autour de DCP ancrés, en utilisant de façon combinée : échosondeur, caméra vidéo sous-marine et techniques de pêche conventionnelles en Martinique (petites Antilles). Des campagnes scientifiques mensuelles ont été menées autour de 2 dispositifs de concentration de poissons ancrés à 2000-2500 m de profondeur, en Martinique d'avril 2003 à avril 2004. L'utilisation combinée d'un échosondeur monofaisceau multifréquence, d'une caméra vidéo sous-marine et de techniques de pêche conventionnelles a permis de déterminer la distribution spatio-temporelle moyenne des poissons agrégés autour des DCP ancrés ainsi que la composition générale des agrégations. Les techniques de vidéo sousmarine ont joué un rôle majeur dans l'identification des espèces et l'observation de leur comportement. De jour; quatre types d'agrégations ont été définis : i) une agrégation de thonidés juvéniles (longueur à la fourche, LF, moyenne : $30 \mathrm{~cm}$ ) observée très près de la surface durant $25 \%$ des périodes diurnes échantillonnées

${ }^{a}$ Corresponding author: mathieu.doray@gmail.com Pacific Islands Fisheries Science Center, NOAA PIFSC,

2570 Dole st. Honolulu, Hawaii 96822, USA 


\begin{abstract}
ii) une petite agrégation composée essentiellement de Caranx crysos présente en surface lors de $65 \%$ des phases diurnes iii) une grande agrégation de thons observée en sub-surface lors de toutes les phases diurnes; cette agrégation était constituée essentiellement de thons noirs (Thunnus atlanticus) de $58 \mathrm{~cm} \mathrm{LF}$, associés de façon saisonnière à des albacores (Thunnus albacares) et des listaos (Katsuwonus pelamis) de taille similaire iv) des grands prédateurs assez dispersés (essentiellement le marlin bleu, Makaira nigricans), observés lors de $10 \%$ des phases diurnes. Une agrégation de sub-surface, aux dimensions plus réduites et composée de thons et «d'extranatants » (poissons restant à distance de 10 à $50 \mathrm{~m} \mathrm{du} \mathrm{DCP)} \mathrm{a} \mathrm{été} \mathrm{observée} \mathrm{lors} \mathrm{de} 75 \%$ des périodes nocturnes; ainsi que des organismes non-identifiés dispersés entre 70 et $400 \mathrm{~m}$ de profondeur. La faible vulnérabilité diurne des thons de sub-surface aux techniques de ligne utilisées indique qu'ils ne se nourrissent pas activement durant la journée. Ces poissons pourraient se nourrir préférentiellement d'organismes mésopélagiques durant les phases de transition et nocturnes autour des DCP ancrés. La pêcherie artisanale martiniquaise n'exploite qu'une faible part des ressources agrégées autour des DCP ancrés. Les principales espèces-cibles sont les grands prédateurs capturés de jour en utilisant des thonidés juvéniles comme appât vivant. L'agrégation de thons de sub-surface représente la grande majorité de la biomasse autour des DCP mais elle est quasiment inexploitée par les pêcheries locales.
\end{abstract}

\section{Introduction}

Moored fish aggregating devices (FADs) have greatly helped to develop and maintain tuna fisheries in tropical and sub-tropical islands (Taquet 1998; Josse et al. 2000). However, better knowledge of aggregative behavior around floating objects is now required to allow for better stock assessment (Hallier 1994; Ariz Telleria et al. 1999) and management (Fréon and Dagorn 2000; Josse et al. 2000; Doray et al. 2006). Moored FADs make convenient oceanic observatories where in situ studies on aggregative behavior can be conducted (Doray et al. 2006; Dagorn et al. 2007). Catch data obtained from commercial (Matsumoto et al. 1981; Cillauren 1994; Kakuma 2000; Doray and Reynal 2003) and scientific fishing (Massuti et al. 1999; Taquet et al. 2000a) have been used to describe fish aggregations around moored FADs, but these data are known to be biased by differences in the catchability of aggregated species and size classes (Fréon and Misund 1999; Josse et al. 2000). The use of direct observational methodologies, namely active acoustics (Depoutot 1987; Josse et al. 1999, 2000; Schaefer and Fuller 2005; Doray et al. 2006) and visual census (Taquet et al. 2000b; Dempster 2004, 2005) allowed to produce fisheries independent assessment of fish aggregations around moored FADs. Active acoustics methods are non-intrusive and provide the most exhaustive description of pelagic fish aggregations (Doray et al. 2006; Josse et al. 1999, 2000). However, experimental fishing (Richards et al. 1991; Gimona and Fernandes 2003; Petitgas et al. 2003; Simmonds and MacLennan 2005) or underwater video surveys (Baamstedt et al. 2003; Ermolchev and Zaferman 2003; Kloser and Horne 2003; Hideyuki et al. 2005) must be conducted simultaneously to assess the composition of acoustic targets (Josse et al. 2000). This paper presents a joint use of echosounding, fishing and video techniques to assess the structure of fish aggregations surrounding 2 moored FADs in Martinique (Lesser Antilles). For each sampling technique, we first assess different "types" of fish aggregation, i.e. distinct fish assemblages consistently observed around the FADs, and precise their mean spatio-temporal distributions. The different spatio-temporal distributions are therefore combined to yield a more accurate picture of the structure of fish aggregations around the FADs.

\section{Materials and methods}

\subsection{Spatial and temporal domain}

In situ data were collected around two FADs moored at 2000 and $2500 \mathrm{~m}$ depth on the leeward coast of Martinique, at 7 ("coastal FAD") and 25 ("offshore FAD") nautical miles from the coast, respectively. Between April 2003 and April 2004, data were collected during 16 monthly cruises aboard the chartered $12 \mathrm{~m}$ commercial fishing vessel "Béryx", surveying both FADs for 50 hours during each sea cruise (Doray et al. 2006).

\subsection{Active acoustics}

The vessel "Béryx" was equipped with a Simrad EK60 scientific echosounder (version 1.4.6.72) connected to two hull-mounted, spherical split-beam transducers (ES38-B and ES120-7G), operating vertically at 38 and $120 \mathrm{kHz}$ frequencies. Each transducer had $7^{\circ}$ beam angles at $-3 \mathrm{~dB}$, with pulse lengths set to $0.512 \mathrm{~ms}$ for both. In situ on-axis calibration of the echosounder was performed before each cruise using standard methodology (Foote 1982). A noise measurement experiment operated at different vessel speeds allowed for the determination of the optimal survey speed of 7 knots (Doray et al. 2006). Acoustic surveys were replayed with the Movies+ software and archived in the international hydro-acoustic data format (HAC) (Simard et al. 1997) at a $-80 \mathrm{~dB}$ threshold. All single echoes with a target strength (TS) greater than or equal to $-55 \mathrm{~dB}$ were selected using the EK60 SIMRAD algorithms (Andersen 2005). The TS threshold was selected according to TS values given in the literature for tuna (Bertrand and Josse 2000). According to preliminary surveys, the majority of the fish biomass was concentrated within a radius of $400 \mathrm{~m}$ around the 2 moored FADs (Doray et al. 2006). A total of 366 star acoustic surveys (Depoutot 1987; Josse et al. 2000 ) of radius $400 \mathrm{~m}$ ("small" star survey) were conducted around the FADs (Fig. 1). In addition, 150 "large" star surveys of radius $1500 \mathrm{~m}$ were operated around midday and midnight during each cruise, to check that fish was consistently concentrated within a radius of $400 \mathrm{~m}$ around the FADs (Doray et al. 2006). In daytime, one small star survey was conducted every 


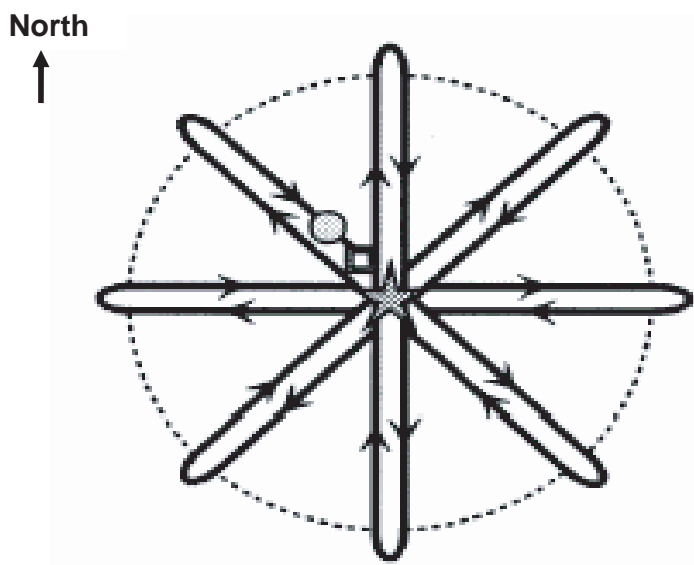

\section{ș FAD head}

\section{- Beginning of the transect}

\section{End of the transect}

Fig. 1. Star acoustic survey design (redrawn from Josse et al. 1999) used around moored FADs in Martinique. The star design radius was 400 or $1500 \mathrm{~m}$.

2 hours around each FAD on average, yielding a mean of 11 small star surveys per cruise.

The $38 \mathrm{kHz}$ frequency provided a global overview of the pelagic ecosystem surrounding the 2 FADs from 10 to $600 \mathrm{~m}$ depth. According to this global sampling, the majority of fish aggregations were distributed within the operational range of the vertical $120 \mathrm{kHz}$ frequency $(10-180 \mathrm{~m})$. This frequency was chosen to characterize fish aggregations because it provided less contamination of fish targets by sound scattering layers (SSL) scatterers than the $38 \mathrm{kHz}$ frequency (Doray et al. 2006).

Acoustic fish shoals and single targets recorded with the vertical $120 \mathrm{kHz}$ transducer were jointly analysed to acoustically characterize fish aggregations. Types of acoustic shoals consistently observed around the 2 FADs throughout all cruises were defined after scrutinizing all echograms. An echointegration-by-shoal algorithm (Weill et al. 1993) was used to isolate pelagic fish shoals from sound scattering layers and to compute mean morphological, positional and density parameters. The mean spatial distribution of each type of pelagic fish aggregation was defined based on these morphological and positional descriptors (Doray et al. 2006). This acoustic data pre-processing procedure was highly time-consuming. It was applied to a subset of acoustic data recorded during 60 daytime and 13 night-time star surveys conducted from April to August 2003. Since similar types of acoustic shoals were consistently observed during all cruises, we assumed that the mean quantitative descriptors of the aggregations detected from April to August 2003 were representative of the mean descriptors of aggregations observed during all sea cruises.

Tree regressions were implemented to identify clusters of single fish targets with similar TS values and spatio-temporal distribution (Doray et al. 2006). This analysis was applied to all TS values (more than 24000) collected during the sea cruises. Equations expressing TS as a function of fork length (Bertrand and Josse 2000; Foote 1987) were used to estimate theoretical mean FLs for each TS clusters. The spatial and temporal overlapping of acoustic shoal and cluster of single target types were tested in order to define fish aggregations with consistent boundaries and obtain their size compositions (refer to Doray et al. 2006 for detail).

\subsection{Underwater video}

We used a light video system to test the feasibility of pelagic fish observations around moored FADs. The video system consisted of a video camera (Sony SST DC 50 AP) placed in a hydro-dynamical housing. The camera was linked to a power supply through a $150 \mathrm{~m}$ coaxial cable tightened on a $12 \mathrm{~mm}$ polypropylene rope. Trawl buoys were attached to the rear part of the housing. This allowed the camera buoyancy to be null and the housing near horizontal in the water. To finely adjust the trim angle, smaller floats were attached to the cable, close to the housing. The camera pitching was limited by attaching a heavy weight of chains to the cable, at about $50 \mathrm{~m}$ ahead of the camera (Fig. 2), absorbing most of the shakes induced by the waves. The video signal was recorded in DVD format with a Pioneer DVR-7000 DVD recorder and displayed in real time on a vessel monitor. A digital depth meter (Uwatec timer) was attached to the housing so it would be visible in the field of view. This device allowed precise adjustment of camera depth in real time. The camera was deployed immediately after daytime star acoustic transects, when significant fish aggregations were detected close enough to the surface to ensure good lighting (usually between 10 to $100 \mathrm{~m}$ depth). The camera was lowered at the end of the coaxial cable above fish aggregations, either when the vessel was drifting (Fig. 2), or when it was attached to the moored FAD. The depth of the camera was adjusted by modifying the length of the cable or by increasing vessel speed. The objective was to maintain the camera within the same depth layer as the aggregation detected with the echosounder. The best video sequences were recorded: i) when the vessel was attached to the FADs and when the current was bringing the camera toward the fish, and ii) while drifting in late afternoon, when the fish was closer to the surface (around $50 \mathrm{~m}$ depth). Acoustic data were stored during video surveys to record in situ TS. We assumed that adding artificial light to the camera would dramatically bias the behavior of fish toward the camera. No video survey was therefore conducted at night.

Fish caught or visually observed around the 2 moored FADs were classified into two groups based on the classification of Parin and Fedoryako (1999), with distance limits proposed by Fréon and Dargorn (2000): "extranatants" (i.e. fishes which remain within 10 to $50 \mathrm{~m}$ of a FAD) and "circumnatants" (i.e. fishes which remain within $50 \mathrm{~m}$ to several nautical miles of a FAD). All underwater video recordings were first scrutinized to identify the main groups of species observed around the moored FADs. The presence or absence of each group was determined for each leg. All video sequences showing fish and recorded between April and August 2003 (13 surveys, total duration: $12 \mathrm{~h} 30$ ) were indexed to be compared to the pre-processed acoustic data. The time and depth of the start and end of each sequence were stored in a database, 


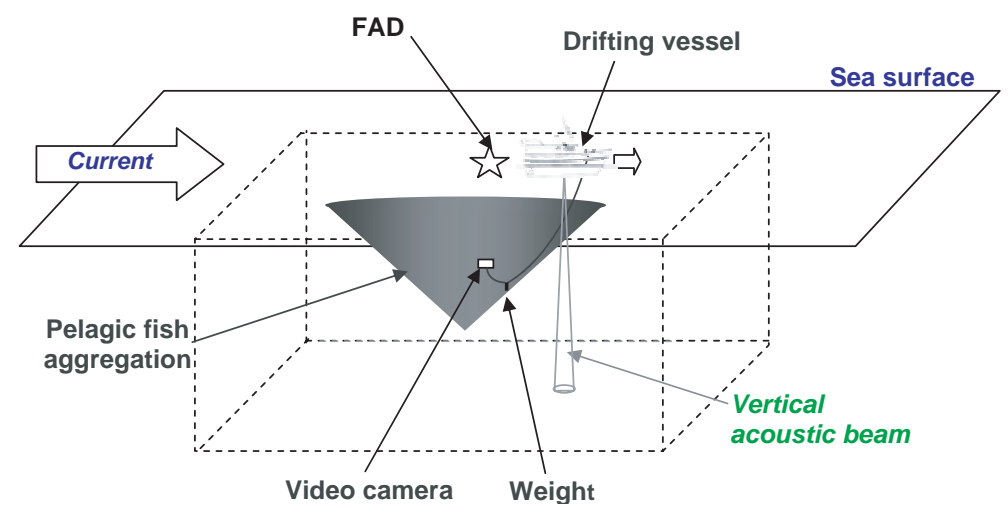

Fig. 2. Drifting survey design used during underwater video recordings around moored FADs in Martinique.

together with information on the species observed, their behavior and the quality of the recording. Mean vertical distribution of each group of species was computed based on this dataset. The total duration of video sequences for which fishes in aggregations could be identified to at least the family level was computed. This value was divided by the total duration of video recordings to calculate the relative amount of time during which video recordings could be used to identify the composition of acoustic shoals. This ratio was used to assess the efficiency of underwater video taxonomic gross identification.

\subsection{Fishing}

Experimental fishing was conducted using surface longline, drifting gillnet and trolling lines. The principal target was tuna with an approximate fork length (FL) of $50 \mathrm{~cm}$. Most of the experimental fishing was conducted during night-time. The longline, made of a $600 \mathrm{~m}$ monofilament main line with thirty $6 \mathrm{~m}$ long branch lines snapped on in $20 \mathrm{~m}$ intervals, was routinely attached to the moored FADs, baited with frozen squid and rigged with 92/02 SKR hooks. Each branch line was equipped with a hook timer (Somerton et al. 1988) that indicates elapsed time in minutes between the capture of fish on the line and landing on deck, from which capture time is estimated. The longline was generally set close to the surface at $7 \mathrm{pm}$ and hauled at $8 \mathrm{am}$. A drifting gillnet with length, height, and mesh-size of $300 \mathrm{~m}, 30 \mathrm{~m}$, and $9 \mathrm{~cm}$ knot to knot, respectively, was used at nights in the close vicinity of the FADs during 4 sea cruises. This gear was later abandoned because of irregularity of catches and handling time. During daytime, surface trolling lines with artificial lures were used. Two trained observers embarked on Martinican commercial fishing boats to sample their catch during sea cruises. Small scale Martinican fishermen mostly fish during daytime by trolling near the surface for juvenile tunas, which are then used as live bait on single hook vertical drifting longlines to catch large top predators (Doray and Reynal 2003). Trolling lines sampled a very superficial depth layer $(0-30 \mathrm{~m})$, while longlines were deployed to depths of 20 to $200 \mathrm{~m}$ (Taquet et al. 2000a).

Data recorded by observers and during experimental fishing included fish species, FL, location and time of catch, and gear type. The number of commercial and experimental catches collected during each monthly sea cruises were usually
Table 1. Number of fish sampled by experimental and commercial fishing per month and FAD. The coefficient of variation is the ratio of the standard deviation over the mean.

\begin{tabular}{cccc} 
& \multicolumn{3}{c}{ FAD } \\
\cline { 2 - 4 } Month/Year & Coastal & Offshore & All \\
\hline April 2003 & 0 & 7 & 7 \\
\hline May 2003 & 0 & 174 & 174 \\
June 2003 & 0 & 26 & 26 \\
July 2003 & 1 & 105 & 106 \\
Aug. 2003 & 5 & 0 & 5 \\
Sept. 2003 & 42 & 21 & 63 \\
Oct. 2003 & 64 & 33 & 97 \\
Nov. 2003 & 10 & 40 & 50 \\
Dec. 2003 & 9 & 20 & 29 \\
Jan. 2004 & 19 & 0 & 19 \\
Feb. 2004 & 35 & 12 & 47 \\
March 2004 & 86 & 20 & 106 \\
April 2004 & 24 & 1 & 25 \\
Total & 295 & 459 & 754 \\
Mean & 23 & 35 & 58 \\
Coefficient of & & & \\
variation (CV) & $120 \%$ & $141 \%$ & $86 \%$ \\
\hline
\end{tabular}

low and highly variable (Table 1). Fishing data were therefore analyzed at the scale of all sea cruises to cope with monthly variability. We defined size classes in the catches, by applying K-means clustering (KMC) (Hartigan and Wong 1979) on size distributions of catches obtained with each fishing gear. As fishing gears sampled different depth layers at different times, this clustering procedure allowed to identify groups of species of similar size displaying identical mean spatial and temporal distribution. This procedure was successively applied on size distributions obtained from commercial, experimental and total catches and the results were compared.

\subsection{Combination of acoustic, fishing and video results}

Mean sizes inferred from TS data for each type of acoustic shoals were compared to mean sizes obtained from clustering of catch sizes. This allowed for selection of species found in the catches that could comprise the acoustic shoals. Spatial and temporal distribution of catches and acoustic shoals were compared to detect overlapping depth layers and/or time periods. 
Hypothesis on the composition of large pelagic fish aggregations were formulated based on this first analysis. Underwater video observations of fish comprising the aggregations were used to corroborate these hypotheses.

Results of fisheries dependant and independent methodologies used in this study were further compared to grossly assess the proportion of each kind of fish aggregation exploited by fishers. We assumed that the relative number of TS allocated to each type of aggregation was a reasonable estimate of the true relative abundance of the aggregations. Then, we compared these proportions to the relative number of fishes in the catches, which were presumably taken from the same aggregations

\section{Results}

\subsection{Active acoustics}

The types of fish aggregations observed around the two surveyed FADs were similar during all cruises. The aggregations occupied two depth layers defined as: "surface" (0 to $35 \mathrm{~m}$ depth) and "sub-surface" (35 to $100 \mathrm{~m}$ depth). The main type of pelagic fish aggregation observed during this study was a single large sub-surface aggregation (mean barycenter depth $=55 \mathrm{~m}$, standard deviation, $\mathrm{SD}=15 \mathrm{~m}$ ). This aggregation was observed during all daytime periods within a radius of $400 \mathrm{~m}$ of both FADs (mean distance $=80 \mathrm{~m}, \mathrm{SD}=$ $41 \mathrm{~m}$ ). A smaller "surface" aggregation was observed closer to the surface (mean barycenter depth $=24 \mathrm{~m}, \mathrm{SD}=4 \mathrm{~m}$ ) and closer to the FADs (mean distance from FAD $=36 \mathrm{~m}, \mathrm{SD}=$ $21 \mathrm{~m}$ ) in $65 \%$ of daytime periods. Mean TS values detected at the $120 \mathrm{kHz}$ frequency inside the aggregations in the daytime were significantly lower in the small surface aggregation (TS mode $=-46 \mathrm{~dB}$ ) than in the large sub-surface aggregation (TS mode $=-35 \mathrm{~dB}$ ). Very high TS values (mean TS $=-18 \mathrm{~dB}$ at $120 \mathrm{kHz}$ ) seemingly produced by large scattered fish were observed around both FADs in $16 \%$ of daytime periods. A single sub-surface aggregation was detected in $75 \%$ of night-time periods (mean barycenter depth $=42 \mathrm{~m}, \mathrm{SD}=17 \mathrm{~m}$ ). Scattered single targets (mean TS $=-40 \mathrm{~dB}$ ) were also observed at night at $38 \mathrm{kHz}$ in the $70-400 \mathrm{~m}$ depth layer, up to $1500 \mathrm{~m}$ from the FADs.

\subsection{Underwater video}

A total of 45 underwater video drifting surveys (mean duration $=60 \mathrm{~min}$ ) and 12 stationary experiments (mean duration $=105 \mathrm{~min}$ ) were conducted during the sea cruises, accounting for a total of 66 hours of recordings. Based on scrutinizing the video data recorded between April and August $2003,21 \%$ of the total duration of video recordings could be used to grossly identify the fish aggregations detected with the echosounder. Fish communities observed around the 2 FADs were very similar. "Extranatants" have been observed during 3 video sequences (total duration: $12 \mathrm{~min}$ ). The majority of "extranatants" was made of a loose aggregation of juvenile blue runners (carangids) (Fig. 4a), mixed with rainbow runners, Elagatis bipinnulata, balistids and dolphinfishes: Coryphaena

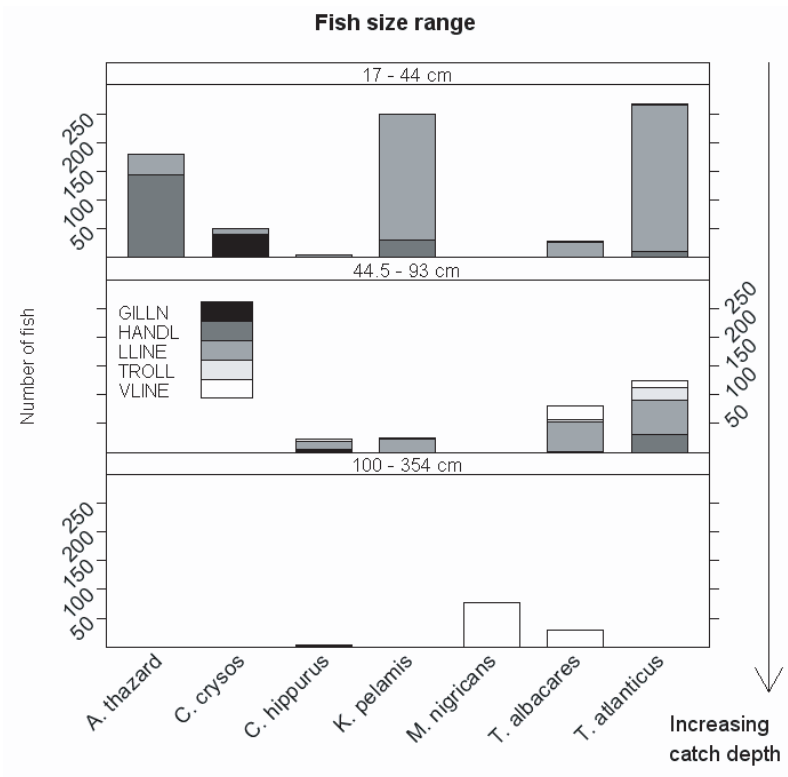

Fig. 3. Species composition of catches by size stratum and fishing gear. Gear codes: GILLN: drifiting gillnet, HANDL: handline, LLINE: surface horizontal longline, TROLL: trolling line, VLINE: vertical drifting longline.

hippurus and Coryphaena equiselis. Blue and rainbow runners were attracted toward the camera and could be easily observed close to the surface at $15 \mathrm{~m}$ depth on average $(\mathrm{SD}=9 \mathrm{~m})$.

Circumnatants have been observed during 22 sequences (total duration: $18 \mathrm{~min}$ ) from $30 \mathrm{~m}$ to $100 \mathrm{~m}$ with natural light. They were comprised of tuna loosely aggregated (Fig. 4b) in the sub-surface layer, at a mean depth of $68 \mathrm{~m}$ depth $(\mathrm{SD}=$ $16 \mathrm{~m}$ ). They generally exhibited avoidance behavior toward the camera. Tuna species can not be distinguished by eye in the video recordings. Further, the length of fishes could not be estimated with our video system because it did not provide information on the distance between the camera and the visual target. Tunas alternatively exhibited 2 swimming patterns punctuated by quick turns: i) a passive dive behavior when the fish was slowly gliding down due to its negative buoyancy, with pectoral fins extended and no tailbeat, and ii) an active ascending swimming pattern with quick tailbeats. Very active and fast tunas followed nearly vertical trajectories whereas calmer fish followed more horizontal trajectories. Feeding behavior was seldom observed.

\subsection{Fishing}

A total of 754 fish were sampled by experimental and commercial fishing from January 2003 to April 2004 (Table 1). The species/size compositions of the catches were similar around the 2 FADs. Size strata defined by K-means clustering were similar for experimental and commercial catches (Table 2), except for the larger size class that was not sampled by experimental gears. Four size strata were defined based on all fishing data: small fishes (mean FL $30 \mathrm{~cm}$ ), medium fishes (mean FL $55 \mathrm{~cm}$ ) and two other strata comprising larger fishes (135 and $253 \mathrm{~cm}$ mean FL), which were later merged into a single 


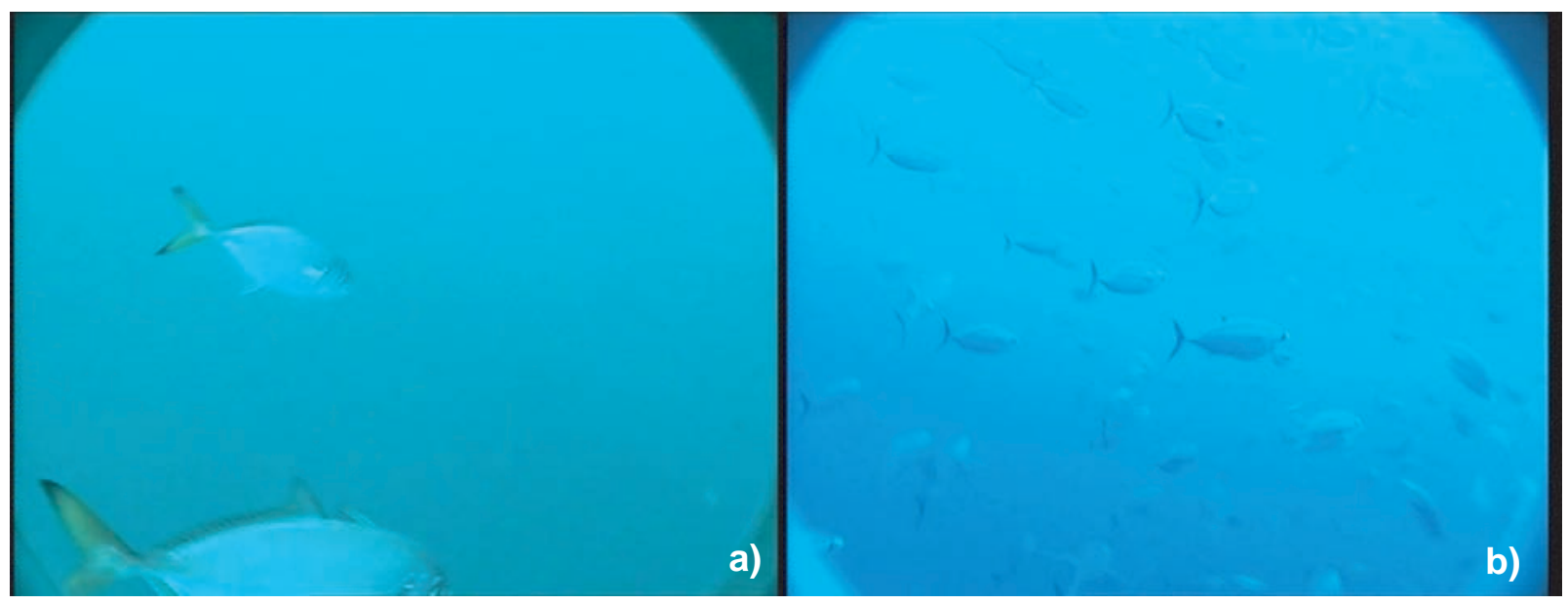

Fig. 4. Examples of underwater pictures taken: a) in an "extranatant" aggregation b) in a sub-surface tuna aggregation.

Table 2. Results of K-means clustering of fish sizes (fork length) for experimental and commercial fishing data.

\begin{tabular}{cccc}
\hline Origin of data & Stratum nb. & Range $(\mathbf{c m})$ & Mean FL $(\mathbf{c m})$ \\
\hline \multirow{2}{*}{\begin{tabular}{c} 
Experimental fishing \\
\cline { 2 - 4 }
\end{tabular}} & 1 & $17-44$ & 28 \\
\hline \multirow{2}{*}{$\begin{array}{c}\text { Commercial fishing } \\
\text { (observers) }\end{array}$} & 2 & $46.5-195$ & 63 \\
\cline { 2 - 4 } & 2 & $17.5-44.5$ & 32 \\
\cline { 2 - 4 } & 3 & $45-93$ & 58 \\
\hline \multirow{2}{*}{ Both } & 4 & $100-193$ & 136 \\
\cline { 2 - 4 } & 2 & $196-354$ & 254 \\
\cline { 2 - 4 } & 3 & $17-44$ & 30 \\
\hline & 4 & $100-193$ & 58 \\
\hline
\end{tabular}

"large fishes" stratum. The species composition of catches by size stratum and fishing gear is presented (Fig. 3).

Small fishes represented $68 \%$ of the total number of commercial and experimental catches. They were mainly caught close to the surface during mornings by commercial fishermen using trolling lines. A substantial amount of small tuna was also fished at nights with the experimental drifting gillnet. Small fishes were dominated by juvenile tuna with the following composition: $34 \%$ of blackfin tuna, $31 \%$ of skipjack tuna, and $21 \%$ of frigate tuna Auxis thazard thazard. Some small fishes were also caught with handlines very close to the FADs. The majority of these catches was blue runner with a mean FL of $19 \mathrm{~cm}$. Medium fishes represented $22 \%$ of the total number of commercial and experimental catches. About $50 \%$ of these medium fishes were adult blackfin tuna, mainly caught by commercial fishermen. Most of medium blackfin tuna catches were made using trolling lines close to the surface in early morning. Medium blackfin tuna were less frequently caught at sub-surface with drifting vertical longlines in daytime. A substantial amount of this fish was also caught during experimental fishing at night with drifting gillnet and surface horizontal longline. Medium sized juvenile yellowfin tuna and skipjack tuna were also fished during 8 cruises out of 12 during which medium-sized fish catches were reported. Yellowfin tuna accounted for $30 \%$ of medium fish catches and was equally caught close to the surface in early morning with trolling lines and at sub-surface in daytime with drifting vertical longline. Skipjack tuna (10\% of medium fishes) were also caught in daytime with trolling lines. Large fishes represented $10 \%$ of the total number of commercial and experimental catches. These catches were essentially comprised of large top predators dominated by adult blue marlin (67\% of total number of large fishes) and yellowfin tuna (24\%). These fishes were mainly caught with drifting vertical longline in the middle of the day.

\subsection{Structure of fish aggregations around the 2 moored FADs}

Information on the vertical diel distribution and composition of fish aggregations provided by acoustics, fishing and underwater video is summarized in Figure 5. Small tuna were distributed too close to the surface to be detected by the vertical transducers and could not be distinguished from medium tuna on video recordings. Their presence around the moored FADs was confirmed by fishing data and daytime visual observations.

"Extranatants" were caught close to the FADs, within the depth range of the small surface aggregation detected at each FAD with the echosounder. As no specific TS/FL relation was available for this species, we applied the general model for physoclistous fish at $38 \mathrm{kHz}$ (Foote 1987) to the average length 


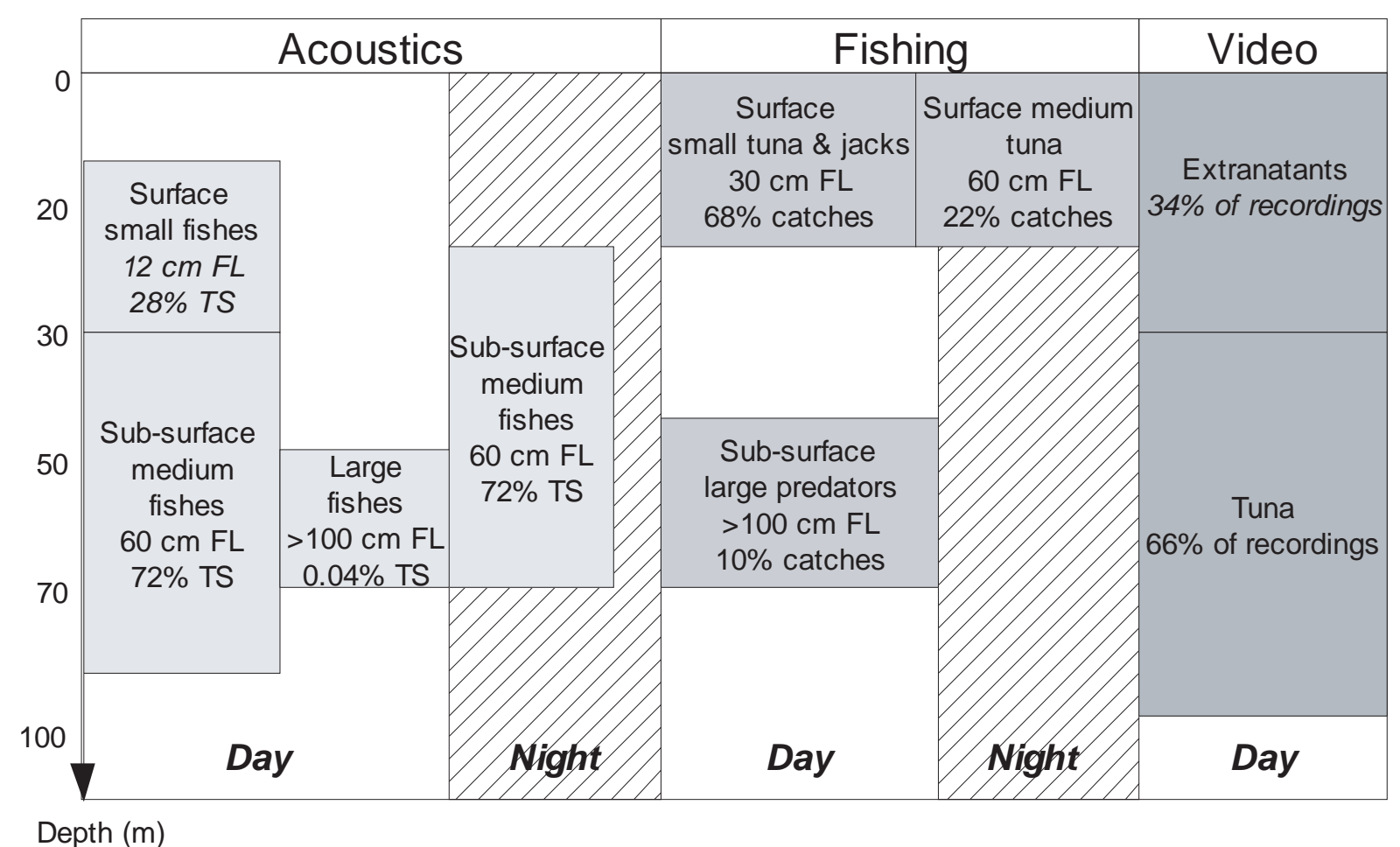

Fig. 5. Summary of vertical diel distributions of pelagic fish aggregations defined based on acoustic, fishing and video data.

of blue runners, obtaining a theoretical mean TS of $-42 \mathrm{~dB}$ for all "extranatants". This value is close to the mean in situ TS recorded within the small surface aggregation $(-46 \mathrm{~dB})$. Underwater video recordings confirmed that the small surface aggregation was made of "extranatants" dominated by blue runners.

Mean sizes of blue marlin and large yellowfin tuna caught around moored FADs were $250 \mathrm{~cm}$ upper jaw-fork length and $140 \mathrm{~cm}$ FL, respectively. No specific TS/FL equations are available in the literature for blue marlin and large yellowfin tuna. However, according to general theoretical TS/FL equations (Foote 1987), such large fishes would produce TS values of at least $-25 \mathrm{~dB}$. These values are compatible with the very high TS values recorded during the sea cruises.

The average FL of medium fish caught around moored FADs was $58 \mathrm{~cm}$. A yellowfin tuna of $58 \mathrm{~cm}$ FL has a theoretical TS of $-36 \mathrm{~dB}$ at the $38 \mathrm{kHz}$ frequency (Bertrand and Josse 2000). The mean in situ TS recorded within the subsurface aggregation at $120 \mathrm{kHz}$ during the sea cruises was very close to this theoretical value $(-35 \mathrm{~dB})$ (Doray et al. 2006). Medium fish were comprised of a majority of blackfin tuna. Yellowfin and blackfin tunas have similar swimbladder volumes and TS within this size range (M. Doray unpublished data). Therefore, medium tuna appeared to be the only fish caught around moored FADs that could have produced TS values recorded within the sub-surface aggregation. However, the spatio-temporal distribution of medium size fishes defined based on acoustic and fishing data do not match (Fig. 5). In fact, medium size tuna were mostly caught close to the surface at night whereas the medium fish aggregation was generally observed within the sub-surface layer during daytime.
Substantiating the acoustic results, tunas have been observed on video recordings during all of the 44 daytime periods when the camera was hauled within the large sub-surface aggregation. This direct video identification indicates that the daytime sub-surface aggregation was comprised of tuna. As medium tuna was the only group of fishes identified in the sampled catches that could have produced TS values recorded within the daytime sub-surface aggregation, we concluded this aggregation was comprised of medium tuna. In the same way, we assumed that the night-time sub-surface aggregation was made of medium tuna possibly mixed with "extranatants". Fishing data did not provide information on deep single acoustic targets detected at night around either of the moored FADs. These single targets remained unidentified. The typology of pelagic fish aggregations observed around the 2 Martinican moored FADs is summarized in Figure 6.

According to TS data, sub-surface tunas accounted for the large majority of fish aggregated around the two moored FADs in Martinique (72\%) (Table 3). Small surface tuna represented an uncountable proportion of the "extranatants" TS (28\%) and large top predators represented a very small proportion of the total number of aggregated fishes $(0.07 \%)$. Fishing data show contrasting results, with a majority of small surface tuna $(68 \%)$, a lower amount of medium tuna $(22 \%)$ and a higher proportion of large top predators $(10 \%)$. Assuming the two FADs are representative of all FADs in Martinique, Martinican fishermen appear to target species and size classes that only represent a very small amount of the total fish biomass aggregated around moored FADs. Data seems to show that medium sub-surface tunas are very slightly fished whereas they account for a major proportion of fishes aggregated around FADs. 


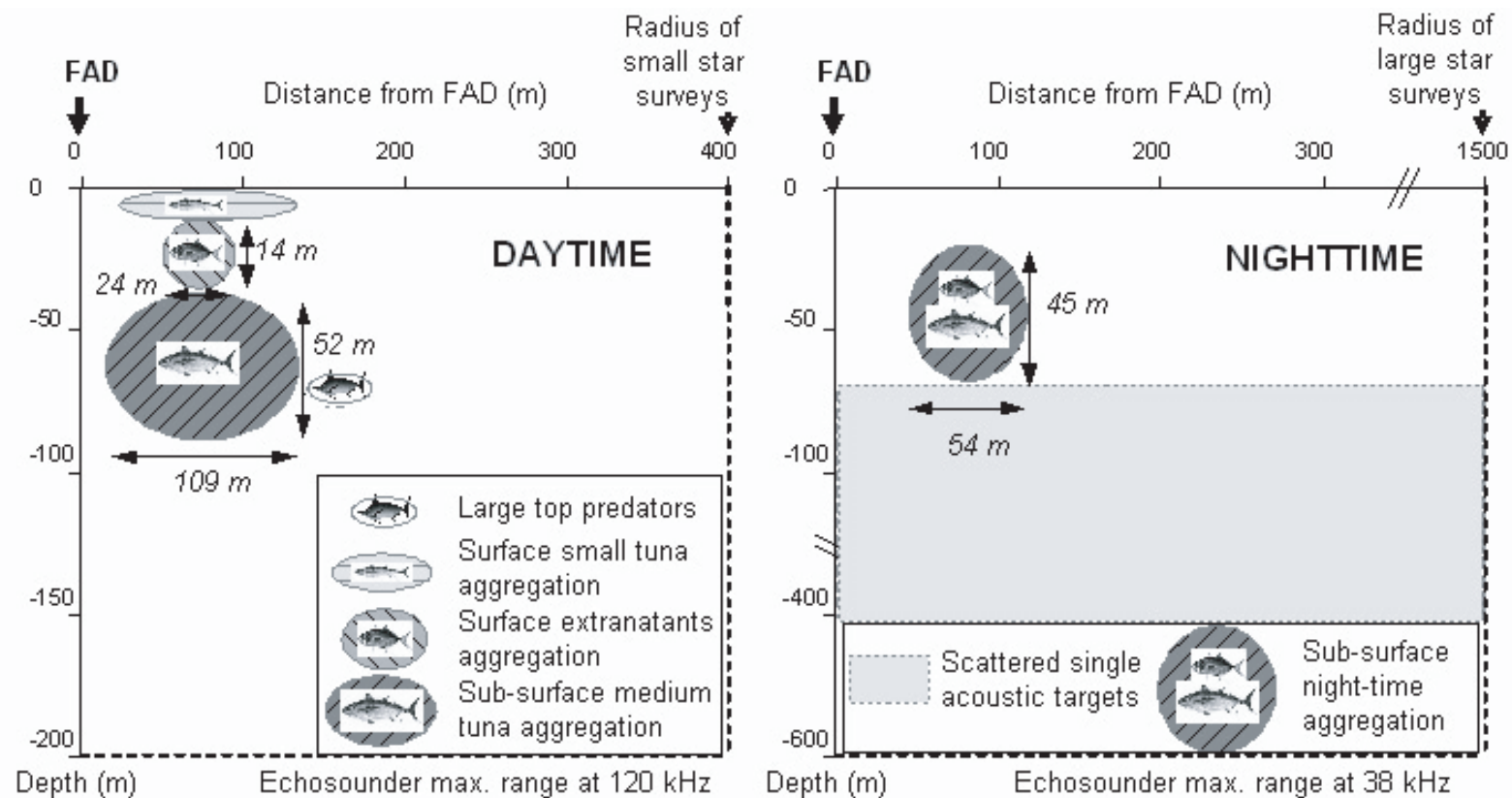

Fig. 6. Typology of pelagic fish aggregations observed in daytime and night-time around 2 moored FADs in Martinique.

Table 3. Comparison of proportions of fish types in target strength (TS) and catches.

\begin{tabular}{lcc}
\hline & $\begin{array}{c}\text { Proportion of } \\
\text { in situ TS }\end{array}$ & Proportion of catches \\
\hline "Extranatants" & $28 \%$ & $68 \%$ \\
Medium tuna & $72 \%$ & $22 \%$ \\
Large top predators & $0 \%$ & $10 \%$ \\
\hline
\end{tabular}

\section{Discussion and conclusion}

This work represents the first characterization of pelagic aggregations around moored FADs combining results from active acoustics, underwater video, and fishing data. Active acoustics provided a unique, near real time overview of the pelagic ecosystem around the FADs. The same types of fish aggregations were acoustically observed around the two devices routinely surveyed for 95 days and around 4 other Martinican FADs that were visited occasionally. This indicates that the types of fish aggregations assessed on the basis of data obtained around the two studied FADs could be representative of fish communities aggregated around most of Martinican FADs. Complementary identification techniques were implemented on the basis of the acoustic results to allocate the acoustic backscatters to species and size classes. This integrated approach allowed for the combination of the strengths and weaknesses of the different sampling methodologies and provided a more accurate picture of the fish aggregations (cf. Fig. 5). Getting significant fishing data on fish aggregations detected with acoustics around the two moored FADs was difficult because no fisheries data collection system was implemented in Martinique. To compound the effects of uncertainty in the quality of the fishing dataset, experimental catches were low and variable. As previously noticed by Taquet et al. (2000a), the gears and baits used to regularly catch medium tuna in night-time did not work successfully in daytime around the two FADs. Moreover, an average of 10 vertical drifting longlines were set around each surveyed FADs by commercial fishermen within the depth range of daytime sub-surface tuna aggregations and yielded very low catches of medium tuna. The highest catches of medium tuna were made around dawn and dusk with trolling lines. The daytime vulnerability of sub-surface medium tunas to the applied line fishing techniques was therefore very low. The vulnerability of a fish to line fishing techniques mainly depends on its feeding motivation and on the attractivity of the bait. We interpreted the low daytime vulnerability of medium tuna to the applied line fishing techniques as a consequence of their low daytime feeding motivation. This is in agreement with theories stipulating that feeding is not the main motivation of tuna while aggregating around FADs; rather, they serve as "meeting points" (Fréon and Dagorn 2000) or as low stress environment (Batalyants 1992) "comfortability stipulation" hypothesis). Most of the tuna concentrated around the two Martinican moored FADs were observed to spread away from the FADs in late afternoon (Doray et al. 2006), when mesopelagic organisms of the deep sound-scattering layers (SSLs) complete their diel migration to the surface and are available in the highest quantity. Stomach content experiments have shown that mesopelagic fishes were an important component of the tuna diet around moored FADs (Brock 1985; Buckley and Miller 1994; Schaefer and Fuller 2005). Moreover, Buckley and Miller (1994) found that yellowfin tuna aggregated around moored FADs in American Samoa mostly fed on mesopelagic fishes during their vertical migration at dawn and dusk. It follows then that tuna could leave the close vicinity of the Martinican FADs 
to forage during transition periods and in night-time. However, since tunas are generally considered as primarily diurnal predators (Buckley and Miller 1994), further stomach content experiments should be conducted on medium sub-surface tuna around Martinican moored FADs to assess if their association with FADs induces changes in their diel feeding behavior. To assess the influence of selectivity issues on the catch data, underwater video surveys were used to provide a direct assessment of families of fishes comprising "extranatant" and subsurface tuna aggregations. Using a remotely operated vehicle equipped with a stereoscopic camera could have improved the camera positioning and provided a direct estimate of fish size. The tuna dive and glide swimming pattern had been previously reported during ultrasonic tracking of yellowfin and bigeye tuna swimming off FADs (Weihs 1973; Carey and Olson 1982; Holland et al. 1990) and is thought to be used at low speeds to save energy during the passive gliding phase (Weihs 1973; Holland et al. 1990). Tuna seem to have adapted this behavior around moored FADs, possibly for similar energy saving reasons.

Video observations have confirmed that the density of fish aggregations detected around the FADs was relatively low (Doray et al. 2006). The number of TS allocated to each type of aggregation was thus assumed to be a reasonable estimate of the true relative abundance of "extranatants" and sub-surface tuna. Due to the shape of the acoustic beam and to the depths preferred by blue marlin and small tuna, it is likely that the number of TS of these fishes were underestimated (Doray et al. 2006). However, acoustic surveys conducted around the same FADs with a transducer set horizontally showed there was no significant fish aggregation within the $0-10 \mathrm{~m}$ depth layer (Doray et al. 2006). We therefore assumed that the number of TS of blue marlin and small tuna was underestimated although not to the extent as to invalidate the result of this study showing that the number of medium tuna TS was 2.6 times higher than those of top predators and "extranatants" (Table 3).

Precise absolute abundance estimates of the large subsurface aggregations of adult tunas observed around Martinican FADs are of prime importance for achieving sustainable development of Lesser Antilles moored FAD fisheries. More accurate abundance estimation methodologies should be applied to medium tuna acoustic data to provide abundance estimates of sub-surface tuna aggregations with confidence intervals.

Acknowledgements. This research was funded by the European Community, the Regional Council and the prefecture of Martinique. The authors gratefully thank the crew of the "Béryx" for their invaluable assistance during the DAUPHIN sea cruises. They also would like to thank Alain Lagin who provided the logistic support for the sea cruises and all the commercial fishermen who took part in the project. The authors are grateful to the FADIO project team for stimulating collaboration and to Réka Domokos for valuable comments and kindly reviewing the English text.

\section{References}

Andersen L.N., 2005, Status and plans for the ER60/EK60. ICES WGFAST Report 2005, ICES CM 2005/B:05, pp. 20.
Ariz Telleria J., Delgado de Molina A., Fonteneau A., Gonzales Costas F., Pallarès P., 1999, Logs and tunas in the eastern tropical Atlantic: A review of present knowledge and uncertainties. In: Scott M.D., Bayliff W.H., Lennert-Cody C.E., Schaefer K.M. (Eds.) Proc. Int. Workshop on the Ecology and Fisheries for Tunas Associated with Floating Objects, Feb. 1992. InterAmerican Tropical Tuna Commission Special Report 11, La Jolla, CA, pp. 21-65.

Baamstedt U., Kaartvedt S., Youngbluth M., 2003, An evaluation of acoustic and video methods to estimate the abundance and vertical distribution of jellyfish. J. Plankton Res. 25, 1307-1318.

Batalyants K.Y., 1992, On the hypothesis of comfortability stipulation of tuna association with natural and artificial floating objects. ICCAT Collect. Vol. Sci. Pap. 40, 447-453.

Bertrand A., Josse E., 2000, Tuna target-strength related to fish length and swimbladder volume. ICES J. Mar. Sci. 57, 1143-1146.

Brock R., 1985, Preliminary study of the feeding habits of pelagic fish around Hawaiian Fish Aggregating Devices or can Fish Aggregating Devices enhance local fisheries productivity? Bull. Mar. Sci. 37, 40-49.

Buckley T.W., Miller B.S., 1994, Feeding habits of yellowfin tuna associated with Fish Aggregation Devices in American Samoa. Bull. Mar. Sci. 55, 445-459.

Carey F.G., Olson R.J., 1982, Sonic tracking experiments with tunas. ICCAT Collect. Vol. Sci. Pap. 17, 458-466.

Cillauren E., 1994, Daily fluctuations in the presence of Thunnus albacares and Katsuwonus pelamis around Fish Aggregating Devices anchored in Vanuatu. Oceania Bull. Mar. Sci 55, 581591.

Dagorn L., Holland K., Itano D., 2007, Behavior of yellowfin (Thunnus albacares) and bigeye ( $T$. obesus) tuna in a network of fish aggregating devices (FADs). Mar. Biol. 151, 595-606.

Dempster T., 2004, Biology of fish associated with fish aggregation devices (FADs): implications for the development of a FADbased fishery in New South Wales, Australia. Fish. Res. 68, 189201

Dempster T., 2005, Temporal variability of pelagic fish assemblages around fish aggregation devices: biological and physical influences. J. Fish Biol. 66, 1237-1260.

Depoutot C., 1987, Contribution à l'étude des dispositifs de concentration de poissons à partir de l'expérience polynésienne. Notes Doc. Océanogr. Cent. Orstom Tahiti 33, 159 p.

Doray M., Reynal L., 2003, Catch per trip variability analysis related to several fishing effort components in the small-scale, large pelagic fishery in Martinique (FWI): an attempt to define more accurate fishing effort units function of the different types of fish "aggregators". Proc. Gulf Caribb. Fish. Inst. 54, 41-59.

Doray M., Josse E., Gervain P., Reynal L., Chantrel J., 2006, Acoustic characterisation of pelagic fish aggregations around moored fish aggregating devices in Martinique (Lesser Antilles). Fish. Res. $82,162-175$.

Ermolchev V.A., Zaferman M.L., 2003, Results of experiments on the video-acoustic estimation of fish target strength in situ. ICES J. Mar. Sci. 60, 544-547.

Foote K.G., 1987, Fish target strengths for use in echo integrator surveys. J. Acoust. Soc. Am. 82, 981-987.

Foote K.G., 1982, Optimizing copper spheres for precision calibration of hydroacoustic equipment. J. Acoust. Soc. Am. 71, 742747.

Fréon P., Dagorn L., 2000, Review of fish associative behaviour: toward a generalisation of the meeting point hypothesis. Rev. Fish Biol. Fish. 10, 183-207. 
Fréon P., Misund O.A., 1999, Dynamics of pelagic fish distribution and behaviour: effects on fisheries and stock assessment. Blackwell Science, London.

Gimona A., Fernandes P.G., 2003, A conditional simulation of acoustic survey data: advantages and potential pitfalls. Aquat. Living Resour. 16, 123-129.

Hallier J.P., 1994, Purse seine fishery on floating objects: what kind of fishing effort? What kind of abundance indices? IPTP Collect. 8, 192-198.

Hartigan J.A., Wong M.A., 1979, A K-means clustering algorithm. Appl. Stat. 28, 100-108.

Harvey E., Cappo M., Shortis M., Robson S., Buchanan J. Speare P., 2003, The accuracy and precision of underwater measurements of length and maximum body depth of southern bluefin tuna (Thunnus maccoyii) with a stereo-video camera system. Fish. Res. 63, 315-326.

Hideyuki T., Matsuda A., Takagi N., Akamatsu T., 2005, Quantitative survey of fish schools near artificial reefs by the optical-acoustic system (fischom). Fish. Engine. 41, 261-265.

Holland K.N., Brill R.W., Chang R.K.C., 1990, Horizontal and vertical movements of yellowfin and bigeye tuna associated with Fish Aggregating Devices. Fish. Bull. 88, 493-507.

Josse E., Bertrand A., Dagorn L., 1999, An acoustic approach to study tuna aggregated around Fish Aggregating Devices in French Polynesia: methods and validation. Aquat. Living Resour. 12, 303-313.

Josse E., Dagorn L., Bertrand A., 2000, Typology and behaviour of tuna aggregations around Fish Aggregating Devices from acoustic surveys in French Polynesia. Aquat. Living Resour. 13, 183192.

Kakuma S., 2000, Current, catch and weight composition of yellowfin tuna with FADs off Okinawa island, Japan. In: Le Gall J.Y., Cayré P., Taquet M. (Eds.). Pêche thonière et Dispositifs de Concentration de Poissons, Ifremer, Actes Colloq. 28, 492-501.

Kloser R.J., Horne J.K., 2003, Characterizing uncertainty in targetstrength measurements of a deepwater fish: orange roughy (Hoplostethus atlanticus). ICES J. Mar. Sci. 60, 516-523.

Massuti E., Morales-Nin B., Deudero S., 1999, Fish fauna associated with floating objects sampled by experimental and commercial purse nets. Sci. Mar. 63, 3-4.

Matsumoto W.M., Kazama, T.K., Aasted D.C., 1981, Anchored Fish Aggregating Devices in Hawaiian waters. Mar. Fish. Rev. 43, $1-13$.
Parin N.V., Fedoryako B.I., 1999, Pelagic fish communities around floating objects in the open ocean. In: Scott M.D., Bayliff W.H., Lennert-Cody C.E., Schaefer K.M. (Eds.), Proc. Int. Workshop on the Ecology and Fisheries for Tunas Associated with Floating Objects, February 11-13, 1992. Inter-American Tropical Tuna Commission Special Report 11, La Jolla, CA, pp. 447-458.

Petitgas P., Massé J., Beillois P., Lebarbier E., Le Cann A., 2003, Sampling variance of species identification in fisheries-acoustic surveys based on automated procedures associating acoustic images and trawl hauls. ICES J. Mar. Sci. 60, 437-445.

Richards L.J., Kieser R., Mulligan T.J., Candy J.R., 1991, Classification of fish assemblages based on echo integration surveys. Can. J. Fish. Aquat. Sci. 48, 1264-1272.

Schaefer K.M., Fuller D., 2005, Behavior of bigeye (Thunnus obesus) and skipjack (Katsuwonus pelamis) tunas within aggregations associated with floating objects in the equatorial eastern Pacific. Mar. Biol. 146, 781-792.

Simard Y., McQuinn I., Montminy M., Lang C., Miller D., Stevens C., Wiggins D. Marchalot C., 1997, Description of the HAC standard format for raw and edited hydroacoustic data, Version 1.0. Can. Tech. Rep. Fish. Aquat. Sci. 2174, 65 p.

Simmonds E.J., MacLennan D.N., 2005, Fisheries acoustics. theory and practice. Blackwell, Oxford.

Somerton, D.A., Kikkawa, B.S., Wilson, C.D., 1988, Hook timers to measure the capture time of individual fish. Mar. Fish. Rev. 50, $1-5$.

Taquet M., 1998, The Fish Aggregating Device (FAD): an alternative to the great fishing pressure on reef resources in Martinique. Proc. Gulf Caribb. Fish. Inst. 50, 249-261.

Taquet M., Guillou A., Reynal L., Lagin A., 2000a, The large pelagic fish of Martinique: biology and exploitation. Proc. Gulf Caribb. Fish. Inst. 51, 375-389.

Taquet M., Reynal M., Laurans M., Lagin A., 2000b, Blackfin tuna (Thunnus atlanticus) fishing around FADs in Martinique (French West Indies). Aquat. Living Resour. 13, 259-262.

Weihs D., 1973, Mechanically efficient swimming techniques for fish with negative buoyancy. J. Mar. Res. 31, 194-209.

Weill A., Scalabrin C., Diner N., 1993, MOVIES-B: an acoustic detection description software. application to shoal species' classification. Aquat. Living Resour. 6, 255-267. 